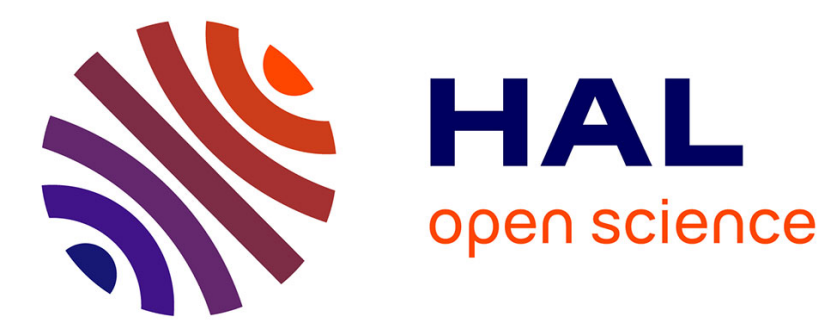

\title{
Morphology development during polymer blending
}

\author{
A. Luciani, J. Jarrin, B. Dewimille
}

\section{To cite this version:}

A. Luciani, J. Jarrin, B. Dewimille. Morphology development during polymer blending. Journal de Physique IV Proceedings, 1993, 03 (C7), pp.C7-1577-C7-1580. 10.1051/jp4:19937247 . jpa-00251885

\section{HAL Id: jpa-00251885 https://hal.science/jpa-00251885}

Submitted on 1 Jan 1993

HAL is a multi-disciplinary open access archive for the deposit and dissemination of scientific research documents, whether they are published or not. The documents may come from teaching and research institutions in France or abroad, or from public or private research centers.
L'archive ouverte pluridisciplinaire HAL, est destinée au dépôt et à la diffusion de documents scientifiques de niveau recherche, publiés ou non, émanant des établissements d'enseignement et de recherche français ou étrangers, des laboratoires publics ou privés. 


\title{
Morphology development during polymer blending
}

\author{
A. LUCIANI, J. JARRIN and B. DEWIMILLE \\ Institut Français du Pétrole, Division Chimie Appliquée Polymères et Matériaux, 1 et 4 avenue de Bois \\ Préau, 92500 Rueil Malmaison, France
}

\begin{abstract}
We present results on the morphologies of incompatible polymer blends analysed by several techniques ( SEM and particle counter after separation). These result show, in the concentration zone just below the inversion phase, the simultaneous presence in the blend of nodular and fibrillar structures.A global interpretation of the phenomena allows us to propose a new relation using the Tomokita notion of fiber stability to predict the phase inversion region.
\end{abstract}

The basic mechanisms involved during blending of two incompatible polymers are particle division, which reduces the size of the dispersed phase, and coalescence, which increases it. The equilibrium between these two competing phenomena under shearing defines the final size and shape of the dispersed phase.

Binary blends were prepared of a polyolefin matrix (PE or PE-co-PP) with a polar polymer (PA6 or PVDF) using an internal mixer (Haake Rheocord EU600). Processing was carried out at temperatures above the melting temperature of the two blend components during 3 to 5 minutes to ensure stable morphologies. Characterization of the dispersed phase in the obtained blends was performed with two different techniques :

1) scanning electron microscopy (SEM) of a fractured surface followed by image analysis to quantify the size of the dispersed phase elements, and

2) dissolution of the matrix phase in a specific solvent followed by filtration of the resulting suspension and subsequent size analysis by an automatic particle counter. This latter technique has the important advantage of analysing a large number $(>1000)$ of particles in a very short time without subjective human intervention. Figures below show a comparison of the size distribution in the nodular domain between the two technics and the fibers content in EP/PVDF blends.

It was found that above a certain critical composition the dispersed phase exists in fibrillar as well as the expected nodular form (1). The filtration step following the dissolution of the matrix phase allowed us to obtain a quantitative separation of the dispersed phase into these nodular and fibrillar fractions. The fibrillar fraction, which is retained on the filter, cannot be clearly seen using classical SEM following fracture or cutting of the materials. 
We have results showing correlations between the size of the nodular phase (that is, the number average diameter measured by the particle counter) and the blending conditions (shear rate, interfacial tension and concentration). As the amount of dispersed phase increases the size of the nodular morphology continues to increase up to a critical composition at which point a fibrillar form is simultaneously present in the blend. This nodular to fibrillar transition take place in the concentration domain just below where phase inversion occurs. Both the size of the nodular phase and the fibrillar content are sensitive to the relative viscosity and interfacial tension of the blend, as well as the shear rate used in blending.
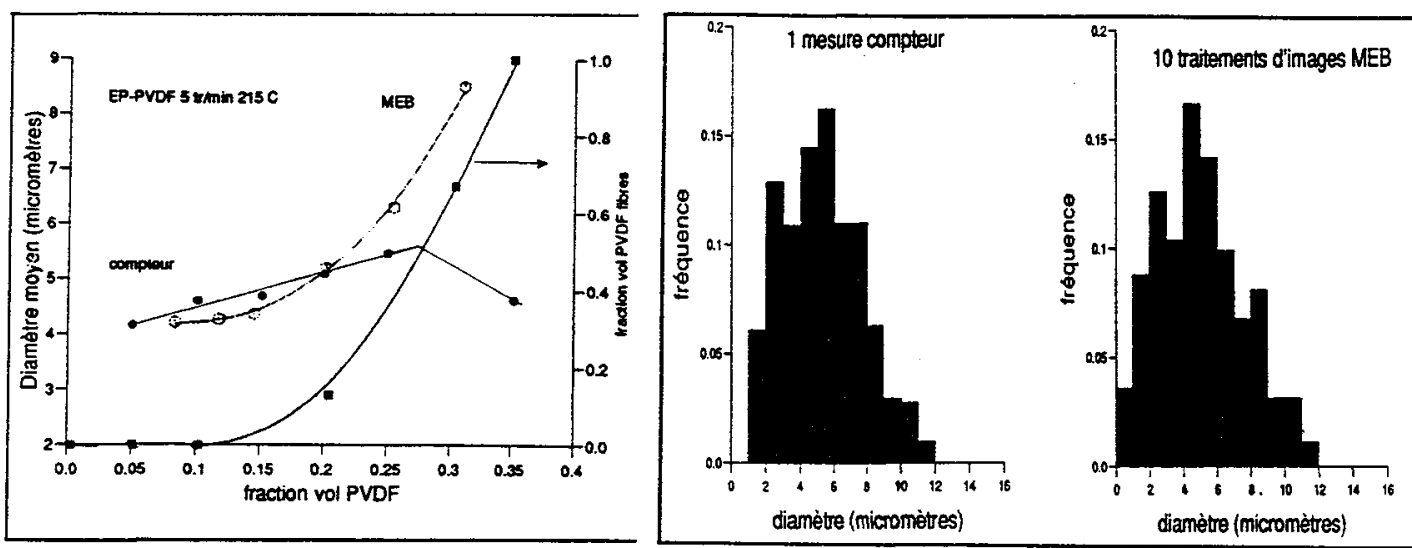

We interpret these results as described in the scheme below.

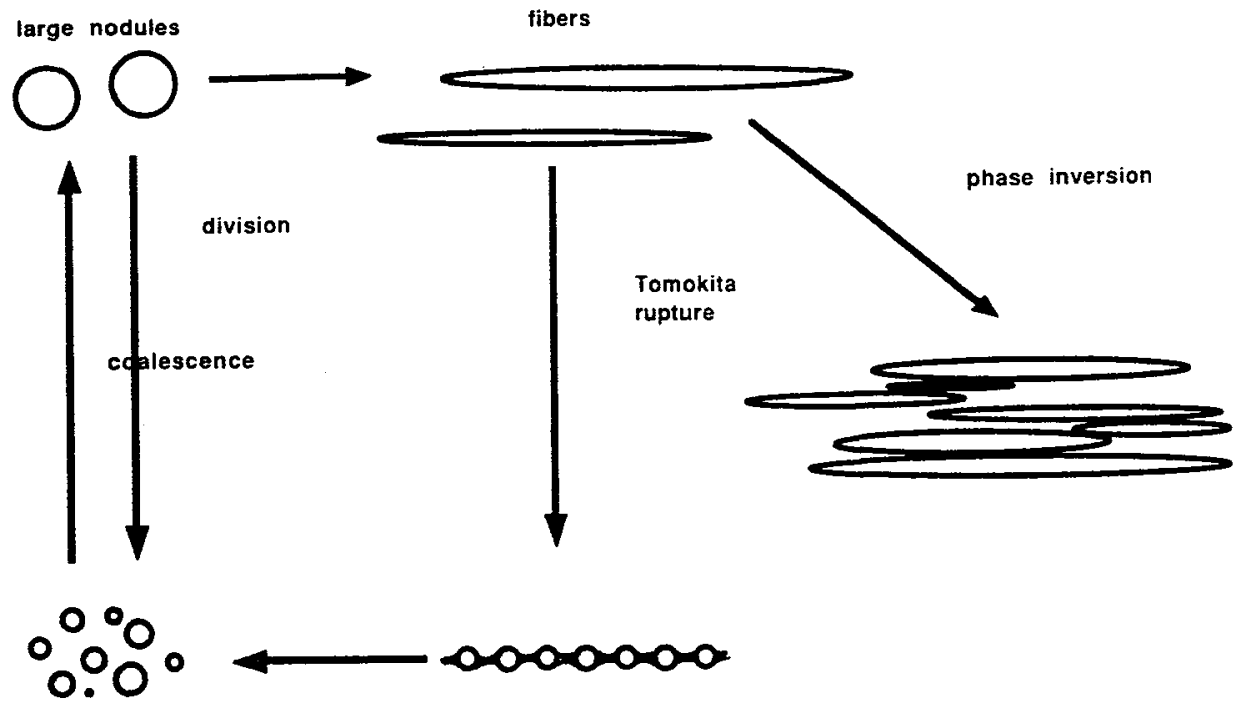

small nodules 
At low dispersed-phase content, there are few interactions between nodules due to shearing and the main mechanism is particle division described by Taylor (2). Coalescence increases with concentration of nodules, and in some cases with shear, leading to an increase in dispersed-phase diameter (3). Eventually, a size domain is reached where the nodules are deformed by shear into a fibrillar form and Rayleigh-type division can subsequently take place. This phenomenon of fibril division without shear has been used to measure the interfacial tension between matrix and dispersed phase in our blends (4). We also present a correlation between a modified Tomokita equation, describing the rate of propagation of instabilities along the fibers that is the stability of the fibers, and the observed concentration at which the nodule to fibril transition occurs. This approach has been extended to predict the phase inversion region.

The usual empirical relation used to predict the phase inversion concentration has been initially proposed by Jordhano and generalized by Miles and Zurek in the form :

$$
\eta 1(\gamma) \varphi 2=\eta_{2}(\gamma) \varphi 1
$$

Experimentally, we found that this relation is not followed when the viscosities of the matrix and dispersed polymers are different.

We propose rather that phase inversion is governed by the stability of the fibrillar structure (described by the $q$ parameter of the Tomokita equations). If the stability of fibrillar form is higher than those of the nodular form, fibers can develop and coalesce to give a cocontinuous structure in the phase inversion zone.

Here, we make the assumption that there is a two-fibrillar network structure in the material. At the phase inversion point, these two fibrillar networks have the same fibers lengths and stability, so that :

$$
q 1=\frac{\sigma \Omega\left(\frac{\eta_{1}}{\eta_{2}}\right)}{\eta_{2} d_{1}} \equiv q_{2}=\frac{\sigma \Omega\left(\frac{\eta_{2}}{\eta_{1}}\right)}{\eta_{1} d_{2}}
$$

Since the diameters $\mathrm{d}_{1}$ and $\mathrm{d}_{2}$ are proportional to the square-root of the composition as

$$
d_{1}=k\left(\varphi_{1}\right)^{0.5} \text { and } d_{2}=k\left(\varphi_{2}\right)^{0.5}
$$

we then obtain the desired relationship :

$$
\left(\frac{\varphi 2}{\varphi I}\right)^{0.5}=\frac{\eta 1 \Omega 2}{\eta 2 \Omega I}
$$


The figure below compare the two equations and table below shows a comparison between the usual equation and those proposed in this paper that is in quite good agrement with the observed values in the whole range of viscosity ratios between the matrix and the dispersed phase.

\begin{tabular}{|c|c|c|c|c|c|c|c|c|c|c|}
\hline Systèmes & $\mathbf{T}$ & $\dot{\gamma}$ & $\eta_{1}$ & $\eta_{2}$ & $\Omega_{1}$ & $\Omega_{2}$ & $\varphi_{1}$ & $\varphi_{1}$ & & $\varphi_{\text {exp }}$ \\
\hline $1 / 2$ & ${ }^{\circ} \mathrm{C}$ & $\mathbf{S}^{-1}$ & $\mathrm{~Pa}_{\mathbf{S}}$ & $\mathrm{Pa}_{\mathrm{S}}$ & & & $\mathbf{8}-\mathrm{a}$ & $\mathbf{8}-\mathrm{b}$ & & (zone) \\
\hline EP/PVDF & 220 & 120 & 1768 & 1090 & $8.85 \mathrm{E}-2$ & $5.67 \mathrm{E}-2$ & 0.38 & 0.49 & & $0.4-0.6$ \\
\hline EP/PA6 & 240 & 120 & 1483 & 147 & 0.218 & $1,94 \mathrm{E}-2$ & 0.9 & 0.53 & & $0.4-0.6$ \\
\hline EP/PA11BV & 240 & 120 & 1221 & 230 & 0.157 & $2.98 \mathrm{E}-2$ & 0.84 & 0.5 & & $0.4-0.5$ \\
\hline
\end{tabular}

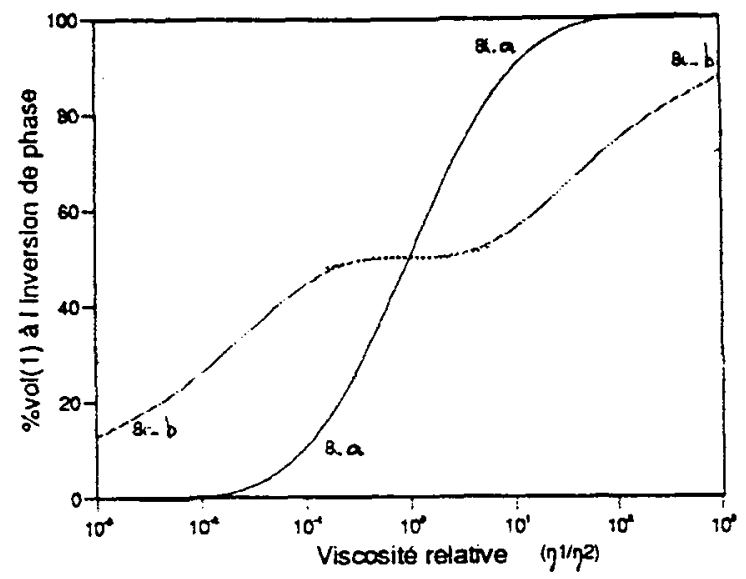

1 : A.Luciani, Thèse ,Ed Technip 1993

2 : G.I.Taylor, Proc.R.Soc, A 138, 41 (1932)

3 : J.J.Elmendorp, Doctoral thesis, (Tech.Univ.Delft) 1986

4 : S.Tomotika, Proc.Roy.Soc, A150, 322 (1935) 